\title{
Instituciones en crisis y acción colectiva frente a las migraciones globales. El caso de la llegada de haitianos a Tijuana, B.C., 2016-2017
}

\author{
AÍdA Silva HeRnÁNDEZ* \\ VianNey Padilla OroZCO**
}

Artículo recibido: 25 de marzo de 2018

Artículo aprobado: 5 de noviembre de 2018

Doi: https://doi.org/10.12804/revistas.urosario.edu.co/desafios/a.6627

Para citar este artículo: Silva Hernández, A. \& Padilla Orozco, V. (2020). Instituciones en crisis y acción colectiva frente a las migraciones globales. El caso de la llegada de haitianos a Tijuana, B.C., 2016-2017. Desafios, 32(1), 1-37. https://doi.org/10.12804/revistas.urosario. edu.co/desafios/a.6627

\section{Resumen}

¿De qué manera las nuevas expresiones de la migración global generan formas de acción colectiva igualmente inusitadas? A mediados de 2016 empezaron a llegar a Tïuana, B.C. (México) cientos de personas de origen haitiano. Las particularidades de su estatus migratorio y el volumen de arribo colocaron a las instituciones civiles y gubernamentales en una crisis ante la inexistencia de politicas especificas para su atención. Partiendo de una discusión teórica-conceptual de acción colectiva y desde

\footnotetext{
* Profesora de la Facultad de Medicina y Psicología de la Universidad Autónoma de Baja California. Correo electrónico: aida.silva@uabc.edu.mx. orCID: http://orcid. org/0000-0002-7979-7192

** Asistente de investigación por proyecto en El Colegio de la Frontera Norte. Correo electrónico: avpadilla22@gmail.com. ORCID: http://orcid.org/0000-0003-3536-603X
} 


\title{
2 I Aída Silva Hernández - Vianney Padilla Orozco
}

una perspectiva metodológica cualitativa, el objetivo del artículo es analizar las relaciones interinstitucionales y el manejo estratégico de recursos de las diversas formas de asociación que surgen en una coyuntura como esta. El estudio muestra cómo en un contexto de crisis institucional las expresiones emergentes de acción colectiva se construyen a partir de redes para responder a necesidades de corto y mediano plazo de la población afectada; asi mismo, se aceleran los procesos de organización civica fundamentados en la solidaridad y se promueve la participación ciudadana a partir de principios identitarios propios de lugares con una larga experiencia migratoria.

Palabras clave: acción colectiva, migración transnacional, instituciones, sociedad civil, globalización.

\section{Institutions in Crisis and Collective Action in Global Migration Contexts. The Case of Haitians' Arrival in Tijuana, B.C., 2016-2017}

\begin{abstract}
How do new forms of global migration generate equally unusual forms of collective action? In mid-2016, bundreds of people of Haitian origin began arriving in Tijuana, B.C., (Mexico). The particularities of their immigration status and the amount of new arrivals placed the civil and governmental institutions in a crisis in the absence of specific policies on attending to them. Starting from a theoretical-conceptual discussion of collective action, and from a qualitative methodological perspective, the objective of the article is to analyze the inter-institutional relations and the strategic management of resources of the different forms of association that arise in such a situation. The study shows how, in a context of institutional crisis, emerging forms of collective action are constructed through networks responding to short and medium-term needs of the affected population, how civic organization processes based on solidarity are accelerated, and how citizen participation is encouraged based on identity principles typical of places with a long migratory experience.
\end{abstract}

Keywords: Collective action, transnational migration, institutions, civil society, globalization. 


\title{
Instituições em crise e ação coletiva frente às migrações globais. O caso da chegada de haitianos a Tijuana, B.C., 2016-2017
}

\begin{abstract}
Resumo
De que maneira as novas expressões da migração global geram formas de ação coletiva igualmente inusitadas? Em meados de 2016 começaram a chegar a Tijuana, B.C. (México), centos de pessoas de origem haitiano. As particularidades de seu status migratório e o volume de arribo colocaram às instituições civis e governamentais em uma crise ante a inexistência de políticas especificas para sua atenção. Partindo de uma discussão teórica-conceitual de ação coletiva e desde uma perspectiva metodológica qualitativa, o objetivo do artigo é analisar as relações interinstitucionais e a gestão estratégica de recursos das diversas formas de associação que surgem em uma conjuntura como esta. O estudo mostra como é que em um contexto de crise institucional, as expressões emergentes de ação coletiva se constroem a partir de redes para responder às necessidades de curto e médio prazo da população afetada; igualmente, se aceleram os processos de organização cívica fundamentados na solidariedade e se promove a participação cidadã a partir de princípios identitários próprios de lugares com uma longa experiência migratória.
\end{abstract}

Palavras-chave: ação coletiva, migração transnacional, instituições, sociedade civil, globalização.

\section{Introducción}

Partiendo de una discusión teórica-conceptual de acción colectiva desde una perspectiva sociológica, el objetivo del presente trabajo es analizar las relaciones interinstitucionales y el manejo estratégico de recursos de las distintas formas de asociación que surgen en el marco de las migraciones globales contemporáneas. Dicho examen se relaciona empíricamente con la llegada a Tijuana, B.C., entre 2016 y 2017, de miles de personas de origen haitiano. Las particularidades del estatus migratorio de estos extranjeros que buscaban asilo en Estados Unidos, unido a su configuración y volumen de arribo, colocaron a las instituciones gubernamentales y civiles de Tijuana en una crisis ante la inexistencia de políticas específicas para su atención. Esto promovió una serie de respuestas ciudadanas y la participación de 
organizaciones no especializadas en migrantes para atender el problema, como las iglesias protestantes, centros educativos y empresas locales. En este escenario se advierte cómo las políticas de los países de destino y de tránsito tienden a presentar condiciones negativas para las personas migrantes, ubicándolos en una suerte de estatus de extranjería permanente (Benhabib, 2004, pp. 14-15), condición que se torna más visible en las zonas fronterizas.

Entendiendo que la acción colectiva es un grupo de individuos integrado como "resultado de intenciones, recursos y límites, con una orientación construida por medio de relaciones sociales dentro de un sistema de oportunidades y restricciones" (Melucci \& Massolo, 1991, p. 358), este estudio parte de suponer que las migraciones masivas que se advierten frenadas en las fronteras geopolíticas pueden llegar a promover formas de participación colectiva caracterizadas por una flexibilidad normativa, operativa y organizacional que antes no se había desarrollado. Que dicha flexibilidad facilita la confluencia de iniciativas ciudadanas de diversa naturaleza que aportan igualmente una variedad de capitales, sean económicos, sociales, políticos e, incluso, simbólicos. Conceptualmente, lo anterior remite a lo que podría considerarse como un nuevo abordaje de la acción colectiva que destaca la capacidad de adecuación de las organizaciones a las realidades sociales actuales (Garretón, 2002, p. 7).

$\mathrm{Al}$ hablar de instituciones se hace referencia a los entes reguladores y ordenadores de las interacciones sociales en sus diversos ámbitos, que a su vez funcionan bajo un conjunto de reglas. La sociedad civil se entiende como las personas y organizaciones de personas que poseen una visión colectiva de sí, cohesionada por la participación y movilización de sus actores hacia la consecución de objetivos "relativamente independientes del Estado, de la actividad política 'profesional' y del mercado" (Boisier, 2002, p. 3). Tratándose de un primer acercamiento al estudio de la problemática, el trabajo se concentra en revisar las dinámicas internas de las nuevas formas de acción colectiva a las que llamamos emergentes y las vinculaciones interinstitucionales que se establecieron en este contexto de migración globalizada. 
Con el objetivo de recuperar sentidos y significados, además de experiencias y opiniones de los protagonistas de esas nuevas expresiones de acción colectiva, se recurrió a una metodología cualitativa a través de entrevistas en profundidad de tipo semiestructurada con integrantes del Comité Estratégico de Ayuda Humanitaria, de la Iglesia del Nazareno y de la Iglesia Camino de Salvación. La investigación incluyó un ejercicio de observación directa en diversas instituciones civiles desde los inicios del arribo de haitianos hasta la fecha; una observación participante en las dos primeras organizaciones mencionadas de octubre a diciembre de 2016; y un seguimiento de la prensa local y de la página de Facebook del Comité. El apartado teórico-conceptual se fundamentó en una revisión y sistematización de la producción académica de autores especializados en acción colectiva.

En la exploración se encontró que, frente a una crisis institucional provocada por un flujo migratorio inusitado para la frontera noroeste de México, las expresiones emergentes o novedosas en la acción colectiva se construyen a partir de redes para responder a necesidades de corto y mediano plazo de la población afectada; así mismo, se aceleran los procesos de organización cívica fundamentados en la solidaridad y se promueve la participación ciudadana a partir de principios identitarios propios de lugares con una larga experiencia migratoria, como lo es Tijuana. Su carácter de 'emergente' obedece a que está protagonizada mayoritariamente por una sociedad civil no especializada en población migrante que decidió orientarse a ella en el momento de la crisis, contando con el apoyo de una participación ciudadana a gran escala.

Estos resultados se explican en tres apartados: el primero consiste en una aproximación teórica a la acción colectiva, el segundo describe el contexto en el que se da la migración de extranjeros de nacionalidad haitiana y el tercero relaciona el planteamiento teórico con este caso en particular, destacando el papel de las instituciones y de la ciudadanía. Cierra con una serie de reflexiones. 


\section{Propuestas teóricas de acción colectiva}

Desde la perspectiva sociológica, la acción colectiva hace referencia a "los escenarios en los que grupos de personas actúan bajo intereses comunes e individuales" (Ostrom, Ahn \& Olivares, 2003, p. 179). Dichos intereses están permeados por diferentes orientaciones en un escenario que implica un sistema de oportunidades y restricciones que modelan sus relaciones (Melucci \& Massolo, 1991, p. 358). Se da bajo una situación de conflicto, de crisis o problema que se pretende subsanar valiéndose del manejo de recursos de distinta índole, ya sean del grupo o de su red de relaciones individuales e institucionales.

En su abordaje, las teorías de la acción colectiva han logrado superar vacíos analíticos al pasar de la tendencia a ponderar un enfoque estructuralista centrado en el estudio de la racionalidad, la pragmática y la expresión de intereses egoístas, a incorporar una perspectiva sociocultural y nutrirse de elementos contenidos en categorías como globalización, democracia, capital social y redes sociales, además de teorizar acerca del papel de la identidad, los sentimientos y las emociones como constituyentes tanto de motivaciones como de finalidades de la acción colectiva (Siegel, 2009; Ostrom, Ahn \& Olivares, 2003; Garretón, 2002; Goodwin, Jasper \& Polletta, 2001). La incorporación de esta pluralidad analítica da pie a un examen de ida y vuelta entre lo abstracto y lo concreto, lo que podría considerarse como una nueva propuesta teórica-metodológica de la acción colectiva, si bien entre los autores no se identifica una conceptualización única al respecto.

Entre las corrientes contemporáneas de acción colectiva se encuentran las teorías del proceso político, de la movilización de recursos y de los nuevos movimientos sociales. ${ }^{1}$ Estas teorías toman fuerza desde los años

\footnotetext{
1 El movimiento social es la forma más compleja de acción colectiva, por lo que "todo movimiento social puede ser considerado como acción colectiva pero no toda acción colectiva puede llegar a convertirse en movimiento social" (Nava, 1997, p. 302). En el escenario de la migración haitiana en Tijuana se estaría hablando de una acción colectiva y no de un movimiento social. Sin embargo, estarán presentes rasgos transversales, ya que las acciones conjuntas en
} 
sesenta y setenta al hacerse cada vez más evidente que los enfoques clásicos y de tendencia estructuralista no alcanzaban a explicar del todo las muestras de acción colectiva que se gestaban en aquellos años, puesto que los enfoques clásicos habían sido utilizados para analizar movilizaciones basadas principalmente en motivaciones de clase, mientras que las nuevas expresiones de acción colectiva no partían necesariamente de las bases, los valores y las ideas tradicionales (De la Garza, 2011, p. 113).

La primera, la teoría del proceso político, se enfoca en las formas y características de las relaciones del sistema político institucional y en la estructura interna de las organizaciones en el marco de la acción colectiva. De acuerdo con Caren (2007), los autores Olson (1965), McCarthy y Zald (1973) y Piven y Cloward (1977) son reconocidos como sus precursores, teniendo entre sus aportaciones la crítica a la irracionalidad pura de los actores, al papel del sistema político y económico imperante, a las oportunidades de acción brindadas por tal contexto y a la manera en que factores como la fuerza de la organización y la presencia de aliados en las élites moldean la potencia y los resultados de la acción colectiva. El mismo Caren señala que dichos aportes fueron retomados en el trabajo de Tilly (1978), que hoy se reconoce como la obra fundacional de la teoría del proceso político, en el cual se conjugan los intereses y las motivaciones como ejes de análisis para interpretar la acción colectiva, además de la organización y las oportunidades (Caren, 2007, p. 2). Es así como un contexto político caracterizado por la apertura de las instituciones, por la estabilidad de las élites y por un nivel de opresión relativo, entre otros elementos, se comprende como un entorno favorecedor para la demostración de acción colectiva.

El énfasis de la teoría del proceso político se encuentra en los conceptos de estructura de oportunidades políticas y en el análisis del llamado "framing" o "encuadre" (Caren, 2007, p. 1). Este último concepto es introducido en la sociología por Goffman (1974), en donde el "marco" ("frame") aparece como "un sistema de entidades, postulados y reglas", o bien en el sentido de "una tradición de comprensión, un 
enfoque, una perspectiva". En ambos casos, la función del marco recae en permitir a los individuos "situar, percibir, identificar y etiquetar un número aparentemente infinito de sucesos concretos" (Goffman, 2006, p. 22), generando un lenguaje en común respecto a la significación de la problemática. Desde mediados de los ochenta, la idea de 'marco' se convirtió en un concepto central en el estudio de la acción colectiva y de los movimientos sociales, ajustándose más adelante como 'encuadre' o 'enmarcado' para brindarle un carácter dinámico, expresando la idea de proceso (Benford \& Snow, 2000, p. 614). El 'encuadre' mantiene así la noción clave del 'marco' como la significación de acontecimientos, pero ahora no lo hace en el sentido de significaciones individuales agregadas, sino como un significado compartido entre los actores involucrados en la acción colectiva que tienen el objetivo de potencializarla, ganar apoyo externo y desmovilizar a la oposición, entre otros propósitos (Benford \& Snow, 2000). Los teóricos del proceso político atribuyen a los participantes de la acción colectiva una conciencia e interpretación de su contexto social, político y económico, en el que identifican un problema y sus causas, y ante ello proponen soluciones (Chihu, 2016, p. 322).

El encuadre se agrupa en tres categorías según sus funciones principales: diagnosticar, pronosticar y motivar. El encuadre diagnóstico se encarga de identificar a los responsables y a las víctimas de la problemática que busca resolver la acción colectiva; el encuadre pronóstico propone las estrategias para solucionar el problema, aumentando la percepción de eficacia de la acción colectiva, a la vez que critica las acciones propuestas por la oposición; el encuadre motivacional resalta el motivo de la acción colectiva y la capacidad de agencia de los actores sociales (Benford \& Snow, 2000).

En ese sentido, ha de tomarse en cuenta que el enmarcado está motivado en alguna medida por las acciones y discursos de las instituciones políticas y de otros actores externos al movimiento (Chihu, 2012, p. 83). Dicho involucramiento se ha trabajado en estudios de gestión migratoria, cuyas bases teóricas se pueden encontrar en la idea de gubernamentalidad expuesta por Foucault (2006, 2007), posicionándose como una idea directriz dentro de las políticas migratorias nacionales e internacionales desde los noventa, en la forma de una 
racionalidad política "que busca modular la conducta de los sujetos migrantes para contener y desincentivar la migración del sur global, para lo cual se recurre a una multiplicidad de tecnologías" (Estupiñán, 2014, p. 249). Según Ghosh, esto ha sucedido en un intento de regular las migraciones de forma que sean más "ordenadas, predecibles, productivas y humanas” (Ghosh en Estupiñán, 2017, p. 5), para lo cual el gobierno ha buscado coordinarse con organizaciones internacionales y no gubernamentales, como las llamadas organizaciones de comunidades basadas en la fe, organizaciones de la sociedad civil y otros colectivos ciudadanos (Desidério, 2015). La coincidencia o divergencia entre los encuadres de cada sector — gubernamental y no gubernamental — se refleja en la intensidad de los vínculos o de los conflictos entre ambos, como se alcanza a reconocer en el caso de los actores involucrados en la migración haitiana en Tijuana.

Por su lado, la teoría de la movilización de recursos, al entender la acción colectiva como formas de acción racional, intencional y organizada, estudia las estrategias y el uso de recursos del conjunto de individuos que llevan a cabo la acción colectiva, entendiendo por recursos "el sistema de medios que permiten u obstaculizan el logro de los objetivos de la acción” (Melucci, 1999, p. 29). Esta teoría surge en Estados Unidos como una aproximación conservadora al estudio de los movimientos sociales, quitando el énfasis en las motivaciones para centrarse en el uso y la disponibilidad de recursos (McCarthy \& Zald, 1973, p. 1). Estos mismos autores señalan que el enfoque es útil para abordar los movimientos sociales "moderados", es decir, aquellos con intenciones de mejorar o aliviar una problemática sin suponer un cambio radical al sistema.

Al igual que en la teoría del proceso político, la teoría de la movilización de recursos discrepa de las nociones tradicionales de la masa irracional, ubicando al individuo y al grupo como un actor que utiliza estrategias, instrumentos y recursos para cumplir con los intereses de la organización (Puricelli, 2005, p. 2). Busca estudiar la correlación entre distintos factores involucrados en el proceso de la acción colectiva que pueden acrecentar o aminorar las posibilidades de cumplir con sus objetivos, tomando en cuenta la disposición de dinero, tiempo y energía. Uno de los ejes de análisis es el nivel de ingreso de los promotores o participantes 
en la acción colectiva, pues existe el supuesto de que al ser mayor el ingreso son también más las posibilidades de que los individuos se involucren en alguna organización. El nivel educativo también se toma en cuenta como propulsor y generador de redes, y como una posibilidad de establecer contactos con ideologías diversas. Otros factores individuales que median la participación son horarios laborales flexibles, clase y estatus social, y relaciones con diversos grupos. De alguna manera, como se explica más adelante, el Comité Estratégico de Ayuda Humanitaria podría ser ejemplo de lo anterior.

A nivel institucional, la teoría de la movilización de recursos pone atención en el papel cada vez más frecuente de las iglesias, el gobierno y las fundaciones como patrocinadores de organizaciones que luchan por alguna causa. Así, la teoría incluye no solo la revisión de las formas de organización interna, sino también la manera en que las élites y el gobierno intervienen en las distintas formas de acción colectiva (McCarthy \& Zald, 1973, pp. 7 y 12). Pensar en una institucionalización de los movimientos sociales lleva a una ampliación del concepto mismo de movimiento social, no limitado a aquellos tipos de acción colectiva como movilización informal en el espacio público, sino involucrando organizaciones formalizadas y bien estructuradas que buscan realizar reformas o aminorar una problemática en específico. Es decir, la acción colectiva se va entendiendo en convivencia con las instituciones formales, no necesariamente contrapuesta. La experiencia Haití-Tijuana sugiere la conveniencia de conciliar ambos tipos de recursos en la búsqueda de solucionar un conflicto, algo parecido a lo que Benhabib (2006) denomina enfoque de "doble vía" en un contexto de multiculturalidad potenciado por las migraciones, en el que son importantes para la discusión y la adaptación tanto las acciones estatales como las distintas formas de acción colectiva. Al respecto, Puricelli (2005) anota que la aplicación analítica de la teoría de la movilización de recursos sobre realidades latinoamericanas debe realizarse con cautela ante las particularidades de los escenarios, sobre todo en lo relacionado con el binomio riquezadesarrollo del movimiento. Con todo, se reconoce que la integración de los ejes de análisis propuestos por esta teoría, y con las adaptaciones necesarias, juega un papel fundamental en la comprensión integral de las muestras de acción colectiva contemporáneas propias del continente. 
Tanto la teoría del proceso político como la teoría de la movilización de recursos, si bien aparecieron como una crítica a las teorías tradicionales de la acción colectiva, han sido cuestionadas por no superar completamente el carácter estructural de sus antecesoras. Partiendo de tal cuestionamiento surge la tercer teoría, la de los nuevos movimientos sociales, que emana de una perspectiva sociocultural para entender la acción colectiva desde las relaciones entre historia, identidad y memoria colectiva, teniendo como objeto de estudio los movimientos que persiguen la democratización y centrando el análisis en el aspecto social de los movimientos, entendidos como una respuesta de oposición al orden establecido en el que los sentidos identitarios juegan un papel fundamental (Chihu, 2000, p. 82). Así mismo, se funda en la raza, el género, la etnicidad y la nacionalidad. Es decir, en la existencia de valores compartidos sobre los cuales se construye ese sentido identitario (Chihu, 1999).

Eventualmente, teóricos como Goodwin, Jasper y Polletta (2001) buscaron fortalecer el sustento cultural de la propuesta, incluyendo el análisis de sentimientos y emociones como promotores de acción colectiva. Entre dichos sentimientos se encuentra la solidaridad, componente esencial de la acción colectiva que genera una 'energía emocional' entre los individuos participantes que los unifica; a este componente aglutinador se suman símbolos o emblemas comunes y sentimientos de moralidad (el sentido de justicia o de bien pretendido), que alientan la vigencia de la acción colectiva (Collins, 2001, p. 28). En los discursos de las personas entrevistadas para esta investigación, el componente emocional destaca como elemento detonante, orientador y justificador de la acción colectiva.

\section{Escenario globalizado: la diáspora haitiana en Tijuana, Baja California, 2016-2017}

La globalización como proceso de cambio social ha resultado en dinámicas migratorias transnacionales potenciadas por un conjunto de factores tanto estructurales como individuales. Se habla aquí de globalización precisamente por la multiplicidad de factores que motivaron la presencia de la diáspora haitiana en la frontera norte de México - económicos, 
políticos, laborales, climáticos, familiares y simbólicos-y por el carácter internacional, intenso, voluminoso y novedoso de esta movilidad, con protagonistas singulares para la región incluso en cuestión de idioma y raza.

El arribo de personas haitianas comenzó a evidenciarse en Tijuana en mayo de 2016, la gran mayoría proveniente de Brasil, que ingresó a México por vía terrestre con la intención de llegar a Estados Unidos para solicitar asilo. ${ }^{2}$ Que se haya concentrado especialmente en esta ciudad fronteriza obedece, por un lado, a la transmisión de información entre los migrantes haitianos que referían a la ciudad como una frontera conocida y relativamente segura; y, por otro, por contar del lado estadounidense con las oficinas migratorias necesarias para tramitar el asilo pretendido (Anónimo, migrante haitiano, comunicación personal, 28 de noviembre de 2016).

La llegada diaria de decenas de personas y el hecho de tratarse de una población extranjera con la intención manifiesta de internarse en Estados Unidos para solicitar asilo hacían prever un tránsito por esta frontera relativamente rápido, aunado a que su estancia en México por razones humanitarias se restringía a un máximo de 20 días. Sin embargo, el pronto ingreso a Estados Unidos no ocurrió. En su lugar, los gobiernos de México y de Estados Unidos implementaron un inusual sistema transfronterizo de citas: antes que los migrantes haitianos llegaran al puerto de entrada de San Ysidro, CA, a pedir su admisión por asilo, como correspondería, ${ }^{3}$ fueron frenados en Tijuana, donde el Instituto Nacional de Migración coordinó la calendarización para que los solicitantes de asilo presentaran sus casos a la Oficina de Aduanas y Protección Fronteriza estadounidense. Con ello, la frontera mexicana fungió como una suerte de estación migratoria; una ciudad-estación

\footnotetext{
2 Para profundizar en el arribo de haitianos a Tijuana, se puede consultar: Alarcón y Ortiz (2017), Albicker, Félix, París, Pérez y Velasco (2017), Yee (2017).

3 Las políticas inmigratorias de Estados Unidos establecen que el asilo solo se puede considerar cuando la persona se encuentra dentro de su territorio, ya sea en algún punto en el interior o en los puertos de entrada. En esos casos y mientras se resuelve su situación, el solicitante permanece en el país bajo custodia de las autoridades (Departamento de Seguridad Nacional, 2018a, pp. 1-2).
} 
abierta en tanto se fueran atendiendo las solicitudes de asilo bajo la cuota diaria, que por períodos osciló entre 30, 50, 80 o 100 personas, insuficiente para desahogar prontamente el volumen de arribo. Fue así que la espera de los haitianos en Tijuana se alargó de "tres meses a más" (Consejo Ciudadano del Instituto Nacional de Migración, 2017, p. 1). Para noviembre de 2016, el Instituto Nacional de Migración había emitido ya 13606 permisos en frontera sur para el tránsito temporal de africanos y haitianos dirigiéndose a frontera norte, ${ }^{4}$ estimándose en cierto momento la llegada a Baja California de 300 personas al día. Entre mayo y noviembre de ese año se calculaba que al menos 8500 personas nativas de Haití habían transitado por Tijuana y Mexicali, B.C. (Sedesol, 2016, p. 46).

Desde el inicio se patentizó una ausencia de políticas de atención por parte de los tres órdenes de gobierno para esta población migratoria sui generis en la región. En noviembre de 2016 era inminente el desbordamiento de la capacidad de apoyo de las organizaciones de la sociedad civil dedicadas a la población migrante o personas sin hogar, como son la Casa del Migrante, el Instituto Madre Assunta, el Ejército de Salvación y el Desayunador del Padre Chava. Esto apremió la participación de instituciones no especializadas en atención a migrantes, principalmente de iglesias protestantes, las cuales tenían cierta infraestructura disponible, pero carecían de logística propia de un albergue, teniendo que implementarla sobre la marcha. En diciembre de 2016 llegaron a contabilizarse 30 albergues a lo largo de la ciudad, entre especializados y emergentes, que hospedaban extranjeros con intenciones de pedir asilo en Estados Unidos (Altamirano, comunicación personal, 20 de diciembre de 2017).

Si bien en Tijuana la relación entre instancias del gobierno local y estatal y las OSC enfocadas en poblaciones migrantes había mostrado

4 Hubo haitianos que se declararon originarios de países africanos por considerar que podía ser favorable para sus objetivos migratorios, como fue el caso del informante de esta investigación que solicitó el anonimato: nacido en Haití, cuando ingresó a México por frontera sur declaró que era nativo del Congo. Esto no descarta que en el flujo haya habido, efectivamente, personas originarias de África. En este trabajo se habla de haitianos por ser la nacionalidad preponderante. 
una coordinación sostenida no solo en términos operativos, sino de incidencia en la agenda pública (Jiménez, Moreno, Figueroa \& Barajas, 2012, p. 135; París \& Müller, 2016, pp. 256-258), el arribo en masa de extranjeros, modalidad sin antecedentes en la región, generó una tensión singular entre ambos actores debido a los encuadres contrapuestos sobre la manera que debía prestarse la atención, retratando al gobierno desprovisto de recursos y en una aparente descoordinación frente a la acción inmediata de la sociedad civil y de la ciudadanía en general.

Las dependencias gubernamentales mostraron "un desconocimiento, una falta de información, mucha cerrazón por parte de los gobiernos de no querer decir ni reconocer nada" (Vázquez, comunicación personal, 16 de septiembre de 2016), reaccionando básicamente en una intervención escalonada: aportación de recursos materiales por parte del municipio como respuesta a solicitudes concretas, eventuales apoyos para la dotación de servicios por parte del Estado y un recurso de 4 millones de pesos para los albergues por parte del gobierno federal, otorgado a través del Instituto Nacional de Desarrollo Social (Vázquez, 2016; Gaxiola, comunicación personal, 23 de junio de 2017; Sedesol, 2016, p. 49).

En medio de la desarticulación de acciones gubernamentales se dio una fuerte exposición mediática sobre la situación migratoria de los haitianos. La ciudadanía se abocó a responder a las necesidades inmediatas de los albergues en cuestión de alimento, atención médica, vestido y enseres de aseo, atendiendo incluso el aspecto emocional a través de actividades lúdicas para esta población en tránsito. ${ }^{5}$ Es importante aclarar que desde años atrás los donativos ciudadanos han sido fundamentales para la operación de los albergues para migrantes. En este caso, la llegada de las personas haitianas lo que promovió fue la diversificación de la participación ciudadana y en un volumen excep-

\footnotetext{
5 A la par de la participación ciudadana solidaria se presentaron expresiones de racismo y xenofobia entre los habitantes de la ciudad. Esas manifestaciones se dieron en el discurso sin llegar a acciones que obstaculizaran los apoyos, de ahí que la percepción generalizada entre los entrevistados fue que las expresiones ciudadanas de colaboración rebasaron ampliamente las manifestaciones contrarias.
} 
cional, desarrollando estrategias de apoyo particulares o conjuntas. Participaron, por ejemplo, estudiantes y profesores de diversos niveles educativos, comerciantes, activistas, empresarios, académicos y artistas. Así mismo, se dieron expresiones solidarias individuales y colectivas desde Estados Unidos, mostrando la interrelación cotidiana transfronteriza que caracteriza a la región.

La coyuntura superó su nivel crítico diez meses después de haber iniciado, alrededor de febrero de 2017, cuando disminuyó el volumen de arribo y cuando la mayoría de solicitantes de asilo había logrado cruzar a Estados Unidos. Para entonces, este país había desalentado el ingreso de haitianos con avisos que recordaban que para obtener el asilo la persona debía encontrarse en una situación de "temor creíble de ser perseguido o torturado" y que, en caso de no probar esta condición, "el Departamento de Seguridad Nacional y el Departamento de Estado de Estados Unidos estaban trabajando con el gobierno de Haití y con otros agentes claves para reanudar las remociones de la manera más humana y menos disruptiva posible" (Departamento de Seguridad Nacional, 2016). Como un indicador de la respuesta que tuvo la población haitiana a sus solicitudes de asilo, se reporta que en el año fiscal $2016^{6}$ se otorgó ese estatus a un total de 127 personas originarias de Haití (Departamento de Seguridad Nacional, 2018b), si bien las estadísticas no alcanzan a precisar quiénes de estos cruzaron por Tijuana. Otro documento de la misma agencia señala que en el año fiscal 2016 el asilo por reunificación familiar (follow-to-join, viable para personas que ya cuentan con asilo en Estados Unidos y piden la entrada al país de familiares cercanos) llegó a 326 individuos de nacionalidad haitiana, representando el 5,9\% del total de asilos de este tipo otorgados en el año (Departamento de Seguridad Nacional, 2018a, p. 8). Los números se dimensionan aún más bajos al tomar en cuenta que durante este flujo extraordinario México emitió al menos 13606 permisos por

\footnotetext{
${ }^{6}$ El año fiscal aludido corre del $1^{\circ}$ de octubre de 2015 al 30 de septiembre de 2016, por lo que la problemática haitiana se refleja parcialmente (de mayo a septiembre de 2016), quedando pendientes los meses álgidos de la llegada a la frontera norte, que fue de octubre a diciembre del mismo año. Al momento de la elaboración de este artículo no se habían publicado los datos del año fiscal 2017.
} 
razones humanitarias a migrantes haitianos, monto que podría acercarse a 18200 si se considera el total de haitianos presentados ante la autoridad migratoria mexicana entre 2016 y 2017 (Instituto Nacional de Migración, 2017, p. 139; 2018, p. 132). ${ }^{7}$

Después de cruzar de Tijuana hacia Estados Unidos, la trayectoria de la población haitiana observaría las siguientes posibilidades: encontrarse retenida en ese país mientras el trámite de asilo estuviera en curso, hallarse en libertad luego de lograr la resolución favorable de asilo, o bien haber sido deportada a su país por habérsele negado. Quienes no llegaron a cruzar pudieron haber optado por dirigirse a otros países de América Latina, asentarse en algún punto del territorio mexicano o quedarse en Baja California, monto que se calcula en alrededor de 3400 personas, 2550 de ellas en Tijuana (Albicker, Félix, París, Pérez \& Velasco, 2017, p. 14).

Es así que en 2017, 2478 haitianos obtuvieron su tarjeta de visitante por razones humanitarias en Baja California (Instituto Nacional de Migración, 2018, p. 121), estatus migratorio que representa una estancia regularizada en el país por un año, factible de renovación. La gran mayoría de los haitianos que se quedaron en Tijuana se independizaron de los albergues emergentes a mediados de 2017, los cuales fueron cerrando sus puertas paulatinamente, si bien el apoyo a la comunidad haitiana para su integración social continuó por parte de varios coordinadores de albergues y de iglesias (Gaxiola, 2017; Altamirano, 2017; Vázquez, 2016).

\footnotetext{
7 Se trata de un aproximado, dado que los "presentados ante la autoridad migratoria" pueden ser objeto de una deportación directa. Es decir, no todos los presentados reciben permiso de salida de la estación migratoria por razones humanitarias.
} 


\section{Componentes de la nueva acción colectiva: actores, contexto, medios, fines y emociones a todo lo largo}

En el escenario descrito destacan los componentes fundamentales de la acción colectiva: una diversidad de actores gubernamentales y civiles, una solidaridad, entendida como "la capacidad de los actores de reconocerse a sí mismos y de ser reconocidos como parte de una unidad social", y un conflicto, "situación en la cual dos adversarios se encuentran en oposición sobre un objeto común” (Melucci \& Massolo, 1991, pp. 360 y 362), percibido también en este caso como el vacío o la incapacidad de un sistema para resolver un problema, requiriendo para ello la intervención de nuevos actores.

Como se señaló al inicio, si bien se examinan las relaciones entre ciudadanía e instituciones gubernamentales y no gubernamentales en la medida que son elementos esenciales de la acción colectiva, el trabajo se centra en la novedad empírica de los actores emergentes en el ámbito migratorio, representados aquí por la Iglesia del Nazareno, la Iglesia Camino de Salvación y el grupo ciudadano Comité Estratégico de Ayuda Humanitaria. La primera Iglesia cuenta con 70 años de presencia en Tijuana; la segunda, con 24 años; y el Comité, con menos de dos, ya que fue creado en septiembre de 2016 en medio de la crisis migratoria.

\section{La arena política de la sociedad civil especializada y emergente}

Antes del arribo de la diáspora haitiana, el panorama de las organizaciones civiles en el entorno migratorio de Tijuana no había mostrado grandes variaciones en alrededor de tres décadas, período en el que la Casa del Migrante, el Instituto Madre Assunta, la Casa YMCA para adolescentes migrantes y el Ejército de Salvación habían y siguen destacando como organizaciones pioneras, robustas, con reconocimiento comunitario y gubernamental, y con capacidad de incidencia en la agenda pública, tres de ellas formando parte de una red consolidada como lo es la Coalición Pro Defensa del Migrante. Sus formas de acción colectiva en la frontera noroeste de México van de lo 
asistencial a la incidencia, caracterizándose por una formalidad en su estructura organizacional y por la capacidad de establecer canales de comunicación para el posicionamiento, la crítica, la coordinación y/o la negociación con los tres órdenes de gobierno.

A estas instituciones se suma el Desayunador Salesiano Padre Chava como otro actor consolidado, con 18 años de funcionamiento y ubicado junto a la línea internacional. Si bien atiende a una población diversa, incluye a migrantes deportados y en tránsito. Durante la crisis, 'el Desayunador' se erigió como un referente concreto y a la vez simbólico de la acción colectiva, ya que al llegar a la ciudad los haitianos se dirigían a este lugar, congregándose en determinado momento por cientos en el interior de sus instalaciones e incluso en la calle, evidenciando la problemática de manera dramática, con el albergue literalmente rebasado. Así mismo, se significó como centro confiable para recibir y administrar una gran cantidad de donaciones ciudadanas, y a su costado se instaló un módulo del Instituto Nacional de Migración (INM) para atender lo relacionado con el estatus migratorio de estos extranjeros. Fue precisamente en el Desayunador del Padre Chava donde coincidieron las personas que posteriormente formarían el Comité Estratégico de Ayuda Humanitaria, quienes entraron como voluntarias de forma independiente al percatarse de la crisis.

Este comité ciudadano se conformó por ocho personas, todas mujeres, concebido por sus integrantes como una respuesta a la necesidad percibida de articular la diversidad de actores participantes en la coyuntura migratoria. Se autorreconoció así como un actor-bisagra para la coordinación o intermediación entre gobierno, medios de comunicación, ciudadanía y albergues, especialmente entre los emergentes, debido a que desde las instituciones consolidadas se le percibió predominantemente como un actor del cual no requerían su intervención (Serrano, comunicación personal, 15 de diciembre de 2016). El Comité quedó integrado en septiembre de 2016 como un equipo de voluntariado, sin figura jurídica, normatividad, estructura organizativa ni presupuesto conjunto, solo con recursos personales. La distribución de funciones se realizó a través de acuerdos de palabra. Sus ejes de trabajo fueron: salud física y mental, vinculación con 
autoridades, organización de donativos, atención a medios de comunicación y actividades recreativas (Reyna, comunicación personal, 5 de julio de 2017). Las integrantes contaban con un capital social y educativo importante, siete de las ocho con estudios universitarios, incluso algunas con posgrado, y varias con experiencia en el activismo, lo que se tradujo en oportunidades y recursos para cumplir con sus objetivos de vinculación. Sus motivaciones fueron la solidaridad y el interés de posicionar la problemática de la migración haitiana en la esfera pública.

De tal manera que en la mencionada crisis sobresale como actor obligado la sociedad civil especializada, que despliega su capacidad de asistencia y de incidencia, además de los actores que se han referido como emergentes, coadyuvantes para soportar el peso de la atención requerida con mecanismos caracterizados por su inmediatez de respuesta. Esta pluralidad civil fue también escenario de negociaciones entre sí, de alianzas o de deslindes por diferencias de representatividad y/o de legitimidad, aun cuando en el encuadre diagnóstico el fin solidario de apoyar a los haitianos les era común. Se trató de una tensión generada por la vibración que provocó la crisis en el orden establecido, pues "las instituciones de atención migratoria consolidadas en la ciudad no reconocieron la existencia y legitimidad del Comité, dado que, como todo campo social que está lleno de conflictos y poderes de vieja data, la llegada de un nuevo agente provocó la sensación de disputa por recursos y posicionamiento" (Serrano, 2016). Esto ocasionó que el encuadre pronóstico relacionado con la estrategia para la solución del problema no coincidiera entre emergentes y tradicionales, mostrándose críticos de las acciones del otro por su desorganización o uso deficiente de recursos (Reyna, 2017), cuando lo que convenía era una coordinación que permitiera otorgar una atención integral (Vázquez, 2017).

Además, las diferencias parecen estar relacionadas con el hecho de que las instituciones especializadas, con décadas de experiencia en la ciudad, se asumen como "actores-sujetos' de acción colectiva que apelan a principios de estructuración, conservación o cambio de la sociedad que tienen cierta 'densidad histórica” (Garretón, 1985, p. 8), 
mientras que los emergentes se encuentran en el inicio de estos procesos y con formas de acción improvisadas ante la premura de atender las necesidades básicas. Tal organización incipiente se percibió desde el Comité como una ventaja, en la medida en que "no teníamos formalidad jurídica, pero contábamos con una autonomía que descolocaba a los actores del campo porque nos salíamos del esquema por todos conocido. Así canalizamos las donaciones del ciudadano común, que rebasó con creces toda la vía formal y tradicional de donaciones" (Serrano, 2016).

La Iglesia del Nazareno y la Iglesia Camino de Salvación albergaron un promedio de 50 a 55 personas, respectivamente (en constante renovación por tratarse de un flujo), explayando sus objetivos ministeriales para poner sus instalaciones a disposición de la población haitiana. Estas iglesias contaban con experiencia previa en el desarrollo de programas sociales propios, pero sin trabajo anterior en el manejo de albergues, rasgo común entre las 22 asociaciones religiosas que colaboraron durante la crisis (Altamirano, 2017). La participación de estas iglesias estuvo motivada por un fuerte sentido ministerial, comunitario y de servicio. En una evaluación retrospectiva realizada en junio de 2017, así expresaba en redes sociales el sentido de su acción el pastor de la Iglesia Camino de Salvación ubicado en la zona este de la ciudad:

Lo hicimos porque esta ciudad es noble, y tiene gente que puede ser generosa para que el bien triunfe sobre el mal [...] Aprovechamos para decirles que pronto habremos de volver a abrir nuestras puertas para recibir a familias deportadas; para seguir ministrando integralmente, y no sólo ofrecer comida y hospedaje. Habremos de seguir uniendo esfuerzos con quienes luchan desde sus respectivas trincheras para hacer de esta ciudad un lugar más amigable para los migrantes, para los que llegan, voluntaria $o$ forzadamente, a intentar tornar a sus lugares de origen o iniciar una nueva vida aquí (Altamirano, publicación en Facebook, 25 de junio de 2017). 
Con esto, el encuadre motivacional de los actores emergentes se distinguió por la ponderación de la identidad migrante de Tijuana, aunado a la idea del 'deber cristiano', principio de las comunidades basadas en la fe para la realización de sus prácticas activistas (Desidério, 2015, p. 95). Queda por verse si prevalecerá a largo plazo la pluralidad que produjo la coyuntura y si marcará un punto de partida en la manera en que las asociaciones civiles relacionadas con la migración seguirán llevando a cabo sus funciones. Considerando que los estudios sobre acción colectiva sostienen que se están dando renovadas expresiones de ciudadanía que interpelan los órdenes establecidos (Delgado, 2007), lo vivido en Tijuana parece que trascenderá los márgenes de la crisis.

Paulatinamente, la comunidad haitiana asentada en la ciudad ha mostrado formas de organización importantes: en mayo de 2017 empezó a funcionar la primera iglesia bautista haitiana autoidentificada para refugiados (Haitian Refugees Outreach Ministries/Ministerio de Ayuda a los Refugiados de Haitî); y en mayo de 2018 las novedades de participación ciudadana que refiere Delgado (2007) cristalizaron en la creación de Visión de los Migrantes, la primera asociación civil en Tijuana dirigida por extranjeros, ${ }^{8}$ quienes mantienen contacto con alrededor de 300 haitianos residentes. Observa entre sus objetivos el asesoramiento para trámites migratorios, la defensa de derechos humanos y el fortalecimiento de lazos sociales, tanto dentro de la comunidad haitiana como en interacción con la comunidad receptora. Es interesante observar que, si bien está encaminada a la defensa de sus derechos como personas establecidas en México, conserva al mismo tiempo una identidad migrante, ya que esta condición constituye el punto central de su acción colectiva. Esto se reitera en su lema "Juntos somos migrantes", destacando la complementariedad del migrante-residente y del distinguirse-formar parte, ambas construcciones características de la memoria colectiva de esta frontera. La representación de los migrantes sin intermediarios es un paso trascendental en la arena de la sociedad civil de Tijuana, advirtiéndose como producto de un aprendizaje y de un agenciamiento trabajado mediante la vinculación con diversos actores sociales, como

\footnotetext{
8 Está constituida por un presidente y ocho consejeros haitianos, contando con el apoyo de un pastor de nacionalidad mexicana para efectos legales.
} 
las iglesias y organizaciones civiles. Pone en evidencia la manera en que se amplía el "espacio político que no solamente expresa una estrategia política, sino también una política cultural que incluye la invención y creación de visiones acerca de la sociedad democrática, en el derecho a ejercer la participación para definir aquello de lo que queremos ser miembros" (Delgado, 2007, p. 57).

\section{Estado, gobierno y sociedad civil}

La situación de la migración haitiana en Tijuana remite a la categoría de enmarcado al existir una conciencia entre la sociedad civil respecto a su lugar en ese contexto económico, social y político, que la hace reconocerse como actor posible de la acción colectiva. Al respecto, y en una muestra de incidencia política con el objetivo de tener "acceso a la esfera pública para transformarla según las necesidades de la comunidad [migrante]" y evidenciando que un "cabildeo efectivo depende de la exitosa vinculación de las osc entre sí” (París \& Müller, 2016, pp. 258 y 259), la Coalición Pro Defensa del Migrante y 22 OsC especializadas en su atención a nivel nacional se pronunciaron a través de un comunicado dirigido al gobierno en primer término - Secretaría de Gobernación, INM y Comisión Nacional de Derechos Humanos-, así como a la sociedad civil y a los medios masivos de comunicación, señalando:

El involucramiento de autoridades mexicanas en la decisión y el control de quién puede presentarse en la frontera sur de Estados Unidos y quién no es ilegal. [...] Denunciamos y señalamos como responsables de esta política antirrefugio a las autoridades mexicanas y estadounidenses al negar el derecho de protección y asilo. Como sociedad civil y defensores de los derechos de las personas migrantes, exigimos al INM que genere un mecanismo que salvaguarde los derechos de las personas que están en búsqueda de asilo, así como de su protección durante su desplazamiento (Coalición Pro Defensa del Migrante y 22 organizaciones firmantes más, 2016).

Ubicado el gobierno en ese papel vigilante, su función de atender/ proteger a las poblaciones migrantes se mostró inoperante y carente 
de una política pública, de un programa y de un presupuesto anticipado para solventar contingencias de esta índole. Se advierte cómo la situación alienta a la sociedad civil a realizar acciones operativas, ya sea interviniendo con trabajo y recursos, y/o demandando a las instituciones gubernamentales una respuesta efectiva al problema (Ostrom, Ahn \& Olivares, 2003). En este caso, exigiendo las garantías que les corresponde a los migrantes en su reconocimiento como sujetos plenos de derechos.

El acuerdo entre los Estados-nación resultó costoso para la población migrante, la que quedó en un estado de 'suspensión social' característico del tránsito en las fronteras geopolíticas: alargó la indefinición de su estatus migratorio, la precariedad de sus condiciones durante el período de espera (ya que sus posibilidades de empleo o de asistencia médica quedan muy limitadas), y en términos emocionales generó una carga agobiante ante la incertidumbre de su porvenir. El permiso que recibieron los haitianos en la frontera sur de México "para regularizar su estancia en territorio mexicano por razones humanitarias" (Instituto Nacional de Migración, 2016) no representaba más que un boleto de paso y salida que a la postre quedó obstruido por los gobiernos mismos de México y de Estados Unidos. Concurre en este marco una potente dimensión estructural. Una gestión migratoria representada por las políticas de control fronterizo internacional, donde los Estados-nación involucrados realizan acciones que muestran un ejercicio de poder en el que, por un lado, el gobierno de México lleva un papel instrumental y, por el otro, Estados Unidos toma el control de mando, al condicionar el acceso a su territorio para retrasar la recepción de las solicitudes de asilo.

Desde la perspectiva de la gubernamentalidad migratoria (Varela, 2015, 2016; Desidério, 2016; Estupiñán, 2014), en particular lo relacionado con la externalización de las fronteras nacionales, tales acciones podrían entenderse como producto de las intenciones de los grandes países de destino de garantizar su seguridad nacional, para lo cual "crean un conjunto de tratados y acuerdos de cooperación que, con la ayuda de países subalternos, 'taponan' los procesos migratorios desde su lugar de origen [y] los corredores de tránsito hasta sus mismas líneas fronterizas” 
(Varela, 2015, p. 5). En ese tenor se encuentran los tratados entre México y Estados Unidos de la Iniciativa Mérida (2008) y el Plan Frontera Sur (2014), los cuales han derivado en medidas de disuasión, retraso, detención y deportación de los flujos migratorios que pretenden transitar de sur a norte (Redodem, 2017, p. 10). La externalización de las fronteras alude así a los filtros que aplica y a la intercepción que realiza México en su frontera sur sobre el paso de migrantes que pretenden llegar a la Unión Americana, mecanismos de control, vigilancia y aseguramiento que además se despliegan a lo largo del territorio, lo que se conoce como frontera vertical (Silva, 2015).

En el caso de los haitianos, la selectividad de los filtros migratorios aplicados por los gobiernos parece dislocada: aun cuando fueron detenidos en la frontera sur de México recibieron permiso de salida de la estación migratoria, lo que les permitió solventar los dispositivos de control propios de la frontera vertical y transitar en grandes grupos hasta Tijuana, donde sí se activaron los dispositivos de control inmigratorio estadounidenses, desalentando y demorando su cruce. Se podría plantear que la contención del flujo en la frontera mexicana obedeció al intento de la diáspora haitiana de internarse a Estados Unidos bajo la figura específica de asilo, ya que se trata de una modalidad que compromete a las instituciones de ese país a más largo plazo que un ingreso indocumentado y abre la posibilidad de una residencia permanente. ${ }^{9}$

En general, la crisis migratoria en Tijuana puso en evidencia que ni el aparato gubernamental ni las organizaciones civiles dedicadas a la atención de migrantes contaban, en sus respectivos ámbitos, con una proyección, una normatividad o recursos para anticiparse a una emergencia de tales características y magnitud, abriendo un espacio de cuestionamiento al modelo de atención. Así mismo, cabría preguntarse por qué resultó tan 'inesperada' la llegada de un flujo semejante

9 Estados Unidos había tenido una experiencia similar en 2014, cuando lograron ingresar a su territorio casi 52 mil menores de edad no acompañados solicitantes de asilo provenientes del Triángulo Norte de Centroamérica (Homeland Security, 2016). En esta crisis las fronteras mexicanas de sur y norte se mostraron ampliamente porosas. 
y qué aptitudes de adaptación y organización requiere en lo sucesivo la gestión migratoria de México, tanto en el interior como en vinculación con Estados Unidos.

\section{“\#Tijuana, ciudad de migrantes”. Identidad y memoria colectiva}

La teoría de los nuevos movimientos sociales que incorpora la memoria colectiva como elemento de la acción supondría que la llegada de haitianos estaría adhiriéndose a la historia migratoria de largo alcance que tiene la ciudad, de tal manera que pudiera observarse cómo "el capital simbólico cargado de emociones reverbera de una movilización a la siguiente. La dinámica del movimiento no es sólo transitoria, sino que se reencarna" (Collins, 2001, p. 43), mientras que el componente emocional está presente en gran parte de las fuerzas causales que se le atribuye a la identidad, a la solidaridad y al enmarcado (Goodwin, Jasper \& Polletta, 2001, p. 6).

Como se comentó, el campo de acción de 2016 y 2017 mostró una participación ciudadana excepcional para Tijuana, diversa en cuanto a nivel socioeconómico, edades y afiliaciones corporativas, aportando insumos y servicios como resultado de un sentido de solidaridad y de una construcción simbólica del 'ser tijuanense'. Esa construcción se encuentra vinculada a la idea de la multiculturalidad fronteriza de Tijuana como ciudad incluyente y con una historia de movimientos migratorios y de experiencias compartidas, por lo que los ciudadanos "al ver la necesidad, dijeron: 'Bueno, si yo puedo ayudar un poquito, lo voy a hacer, porque a lo mejor a mí me ayudaron en algún momento’, porque ¿cuántos no somos migrantes aquí?, ¿cuántos no hemos pasado por una situación así o más complicada?” (Gaxiola, 2017).

Ciertamente, esto no había ocurrido con otras poblaciones extranjeras, como las provenientes de países centroamericanos ni de connacionales desplazados por la violencia desde Guerrero, Veracruz o Michoacán. ${ }^{10}$ De alguna manera, la visibilidad que adquirieron los

10 Una discusión pendiente se relaciona con la invisibilidad de estas poblaciones migrantes en la esfera pública: examinar cuáles son los factores que intervienen 
migrantes haitianos debido a su volumen de llegada, a su formación en grandes grupos y a las distinciones raciales fueron condiciones que pudieron vincularse con cuestiones de identidad, entendiendo que "los símbolos generan un sentido de pertenencia que es compartido por los actores, y los rituales pueden actuar para la comunidad como símbolos de grupo" (Chihu, 1999, pp. 65-66).

La cita de Altamirano (2017) en líneas anteriores, "Lo hicimos porque esta ciudad es noble", hace referencia a ese clima generalizado en Tijuana en los meses en que se evidenció la llegada de haitianos: el componente identitario de la ciudad como un entorno migratorio histórico fue un factor que corrió con un peso importante en los discursos de los diversos actores civiles de la acción colectiva, destacándose como promotores para la ayuda, tal como lo señala Collins (2001) en sus estudios sobre las emociones. Ese recurso identitario fue utilizado expresamente por el Comité en su lema o eslogan "\#Tijuana, ciudad de migrantes", con el objetivo de "colocar a la ciudad como un referente de una ciudad amigable con los migrantes. O sea, queríamos darle esa distinción o ese calificativo e incluso lograr que ese reconocimiento se diera realmente por las organizaciones" (Vázquez, 2016).

Los patrones de participación en la emergencia migratoria sugieren que la ciudadanía se visualizó como tijuanense (nativo o no nativo) y complementariamente como tijuanense capaz de participar en una acción colectiva en respuesta a un compromiso con la ciudad y con una empatía por 'el otro' en relación con 'el nosotros' multicultural característico de la frontera, de tal manera que la dimensión simbólica se vinculó con "su capacidad para transformar las definiciones colectivas de las situaciones problema que motivan su acción, tanto en la dimensión cultural como en la institucional" (Delgado, 2007, p. 47). A este proceso relacionado con la parte cognitiva de la cultura (Goodwin, Jasper \& Polletta, 2001, p. 6), debe agregarse la cuestión motivacional, donde las emociones corren con un papel trascendental. Los

en su atención y por qué no genera una movilización semejante a la de ciertos extranjeros. 
sujetos involucrados en la acción colectiva se muestran conscientes y sensibles de su posición y de la posición de otros dentro del marco político imperante. Reconocen las necesidades y las injusticias que los aquejan, y a partir de las inconformidades compartidas se organizan para enfrentar a los actores identificados como responsables de la adversidad, proponiendo soluciones a las problemáticas. "Nos movemos por emociones realmente, y si logras llegar a esa fibra, la gente responde" (Vázquez, 2016).

A la par de esta estrategia promotora para la consecución de medios - principalmente no materiales — y de fines — posicionar el tema en la agenda pública y atender las necesidades básicas de los migrantes-, las asociaciones emergentes contaron con recursos preexistentes provenientes del manejo de sus respectivos capitales sociales. Las iglesias contaban con aportaciones económicas de su feligresía (algunas no solo localmente, sino de sus filiales internacionales), y con la colaboración y el trabajo conjunto que habitualmente cultivan en el interior y el exterior de sus comunidades. Acostumbrados a trabajar por consenso, el apoyo a las personas haitianas se acordó entre los miembros, asumiéndolo como parte de su ministerio. Nuevamente destaca la flexibilidad de su organización interna para responder a las necesidades observadas, de ahí que aun sin presupuesto definido ni logística anticipada hayan podido participar en el apoyo a migrantes. La Iglesia Camino de Salvación estaba vinculada a su vez con una red de iglesias cristianas que participaron como albergues (Roca de Salvación, Getsemaní, El Calvario, Segunda Iglesia Bautista y La Calle), retroalimentándose de sus experiencias y compartiendo estrategias y donativos. La participación de estas iglesias fue predominantemente asistencial, pero con un poderoso acompañamiento como primera comunidad de acogida.

En cambio, el Comité Estratégico de Ayuda Humanitaria sobresalió por una incidencia política a nivel de agenda, con presencia en medios masivos de comunicación y en las redes sociales. Esto fue posible por la sinergia de capital social entre sus integrantes, solicitando o logrando acceso a colectas de insumos o servicios por parte de la población (artistas, académicos, médicos, comerciantes, entre 
otros), de instituciones de diversa índole (prensa local, nacional e internacional, escuelas, cámaras) e, incluso, estableciendo líneas de coordinación con los gobiernos municipal y estatal. Tuvieron como principal herramienta de comunicación una página de Facebook con 2500 seguidores locales, en el resto de México y en Estados Unidos (Vázquez, 2016). ${ }^{11}$ "Desde Facebook se orquestaba la gestión de los donativos, la logística de recepción-entrega y, sobre todo, la circulación de información que las autoridades quisieron ocultar porque evidenciaba sus incapacidades. En este sentido, se trató de una acción mediática en redes sociales, pero con acción política concreta y con resultados" (Serrano, 2018). Precisamente, las redes sociales han sido objeto de estudio en investigaciones recientes de acción colectiva, reconociéndolas como potenciadoras de "las redes de contacto y el sistema de alianzas de la organización, alcanzando mayores posibilidades de relacionarse con la gente para dinamizar el proceso de concienciación y, por lo tanto, incrementar su potencial de movilización" (Delgado, 2007, p. 64). Para el Comité, "el grupo de Facebook se convirtió en una plataforma de acción social que aglutinó la voluntad y solidaridad ciudadana local” (Serrano, 2018).

La construcción de discursos orales y escritos, el dominio del inglés y el entendimiento de la vida transfronteriza fueron recursos importantes para la gestión del Comité, aspectos considerados en el análisis de los nuevos movimientos sociales, en el que se recalca la importancia del discurso en virtud de que "el dominio de las sociedades complejas descansa en un constante flujo de información. La acción colectiva se ubica en el ámbito cultural y en un mundo regido por el dominio de la información" (Chihu, 1999, p. 60). En palabras de una de las integrantes del Comité: "Nos volvimos como un referente porque teníamos información que no tenía la autoridad [...] Generamos una estrategia mediática porque nadie estaba informando. A nosotros nos parecía importante el tema de la información por dos cosas: para que la ciudadanía supiera lo que estaba pasando y evitar todos

\footnotetext{
11 Página en https://www.facebook.com/search/top/?q=comit $\% \mathrm{C} 3 \% \mathrm{~A} 9 \% 20$ estrat $\%$ C3\%A9gico $\% 20$ de $\% 20$ ayuda $\% 20$ humanita ria $\% 20$ tijuana $\% 20$ (donaciones $\% 20$ y $\% 20$ ayuda)
} 
estos temas de discriminación, xenofobia, y todo eso que empezaban a haber como brotes, [...] y para presionar a la autoridad también" (Vázquez, 2016).

En conjunto, la coyuntura revisada presenta elementos de acción colectiva, como "el conflicto, las solidaridades, el cálculo, la organización, los recursos, los sistemas de creencias y de elaboración simbólica, así como otros actores sociales y políticos que facilitan u obstaculizan el desarrollo de una acción" (Tarrés, 1992, p. 754). Se trata de una expresión contemporánea de acción colectiva que, si se ubica en el espectro de los movimientos propios de las sociedades que experimentan la reconfiguración de nuevas expresiones de ciudadanía frente a las migraciones, acaso estaría representando el principio de una respuesta alternativa para la atención de estas poblaciones migrantes globalizadas.

\section{Reflexiones finales}

Las migraciones en el mundo están transformando las formas de vida ciudadana, sobre todo cuando dejan de figurar como diásporas eventuales y 'de paso' para significarse como factores de cambio dentro de las sociedades. Así sucede actualmente en los casos de Italia, Alemania y España con la llegada de africanos que cruzan el Mediterráneo, en Brasil con la estancia de haitianos, los nicaragüenses en Costa Rica y, más recientemente, el arribo de venezolanos a Colombia, Argentina, Chile, Brasil, Perú y México, entre otros ejemplos. La ciudadanía reacciona a su llegada en diferentes escalas y posicionamientos, lo que puede llevar a manifestaciones con repercusiones mayormente favorables para los inmigrantes, como en el caso revisado, o con afectaciones bastante desfavorables, como ocurre con los sirios y los subsaharianos en ciertas regiones de la Unión Europea, con los venezolanos obligados a marcharse de Brasil (agosto de 2018) y, por supuesto, con los mexicanos en Estados Unidos.

A la luz de las teorías del proceso político, de la movilización de recursos y de los nuevos movimientos sociales, este trabajo tuvo como objetivo realizar un análisis de las relaciones ciudadanas e interinstitucionales que 
entran en juego en la acción colectiva promovida por una migración sui generis para una frontera internacional. En una dimensión política, sobresale cómo el cruce de fronteras está mediado por una gestión migratoria controladora y selectiva de los flujos, gestión que hoy en día parece sostener un especial interés en obstaculizar la recepción de solicitudes de asilo, como lo sugiere el hecho de que los haitianos, los centroamericanos que arriban en modo de caravana (mayo de 2018) y el creciente número de mexicanos desplazados en los últimos tres años sean los grupos de población migrante que están quedando 'atorados' en la frontera norte de México. Los dispositivos propios de la externalización de las fronteras y de la frontera vertical México-Estados Unidos, otrora operando sobre flujos indocumentados de carácter económico y laboral, ahora se enfrentan también a migraciones que buscan un ingreso documentado por razones humanitarias, por persecución y/o por desplazamiento causado por la violencia. Esa intención de ingreso regular en la figura de asilo obliga al aparato migratorio de los gobiernos a asumir la responsabilidad de atender a los solicitantes y de incorporarlos al sistema institucional, resistiéndose a ello con el cierre de fronteras, con muros administrativos y con políticas cada vez más orientadas a ponerle un costo emocional extraordinario a la movilidad, como la separación familiar y la imprecisión en el tiempo de espera que requiere el proceso (que puede extenderse a varios años), a lo que se suma la incertidumbre del resultado y la posibilidad latente de la deportación.

Por su parte, las asociaciones civiles y religiosas de Tijuana, si bien diversas en antigüedad, estructura, normatividad y misión, se unifican en ese lenguaje común señalado por Goffman (2006) al asumir el papel de inquisidores del gobierno, exigiendo soluciones y el respeto al derecho a la dignidad humana, a la justicia, al libre tránsito, al debido proceso, a la no discriminación, al asilo o refugio y a un alojamiento digno (Comisión Nacional de Derechos Humanos, 2016). La movilización de recursos por parte de la sociedad civil señala la trascendencia de sus redes para responder no solo a las necesidades inmediatas que despierta la llegada de extranjeros en cuestión, sino a los requerimientos que han venido presentándose a mediano plazo en sus incipientes procesos de integración. 
Así mismo, la propuesta teórica de los nuevos movimientos sociales da pie a la revisión holística de los elementos tangibles e intangibles que dan sentido a la acción colectiva, como los sentimientos y emociones comprometidos, la identidad, el prestigio y el capital social que desenlazan en acciones solidarias. En el presente examen, el trabajo precursor de la sociedad civil consolidada aparece como promotor de la construcción imaginaria del migrante como una persona necesitada. Ello explica que el apoyo ciudadano múltiple y voluminoso durante la crisis no se haya fraguado a partir del arribo de los haitianos, sino que tuvo sus antecedentes en el tejido histórico y sociocultural de Tijuana como 'ciudad de migrantes’, memoria colectiva capitalizada por los diversos actores.

Es preciso subrayar como resultado posterior a la crisis la muy reciente creación de Visión de los Migrantes, un parteaguas en el escenario de la participación cívica de la ciudad: la comunidad haitiana se aparta del estado de suspensión que la gestión migratoria identifica como 'en tránsito’ para reconocerse en su lugar como actor social y político, logrando un espacio de representación con voz propia para la defensa de sus intereses. Se trata de un encuadre motivacional que destaca su capacidad de agencia y su aprendizaje, obtenido a partir del contacto cercano con iglesias y organismos de la sociedad civil, remitiendo a los principios de la teoría de la movilización de recursos, que estima las estrategias, los instrumentos y los recursos sociales y educativos para el logro de objetivos. También hace referencia a las capacidades formativas y promotoras de ciertas OSC para facilitar la gestación de este otro tipo de asociación.

La revisión da pauta a pensar en políticas que incorporen el potencial de los actores consolidados y emergentes, de gobierno o civiles, así como a los migrantes mismos, hacia una efectiva atención de estas poblaciones en el respeto pleno de sus derechos humanos. En esa pluralidad y finalidad, se sugiere la conveniencia de que el gobierno de México reconfigure sus acciones de control migratorio sujetas al modelo de externalización de las fronteras, el cual, además de sus efectos perversos sobre los migrantes, le genera serios conflictos operativos cuando se trata de poblaciones con fines de asilo en Estados Unidos. La comprensión de los flujos no se restringe actualmente a 
una relación binacional, sino a una movilidad continental, y además es oportuno advertirlos como poblaciones que están tendiendo a establecerse en territorios distintos al destino inicialmente pretendido, con las consecuentes necesidades de inserción laboral y de integración social. Ante ello, se requeriría concretar un marco normativo y protocolos diseñados para ese proceso de tránsito-asentamiento en su conjunto, no por separado, en la medida en que atender la problemática como un solo proceso requiere funciones institucionales muy específicas y no del todo claras en las reglas de operación vigentes (por ejemplo, facilitar la regularización migratoria mediante la residencia temporal o la tarjeta de visitante por razones humanitarias, posibilitar la emisión de documentos de identidad a extranjeros, así como mecanismos para el reconocimiento de grados escolares y de capacitación técnica). El apoyo complementario y coordinado con la sociedad civil y el dar margen al ejercicio de la capacidad de agencia de las personas migrantes-residentes resulta fundamental y precisa una tarea de fondo que se entiende extremadamente compleja por el ejercicio de poder y de intereses implicados en la gubernamentalidad global de las migraciones (Varela, 2015).

Finalmente, los puntos que dimanan de este primer acercamiento y que quedan pendientes de examinar son, entre otros: la recuperación de la propia experiencia de la población migrante y sus posibilidades de protagonizar una acción colectiva en el país; la incorporación de las voces antagónicas o críticas de las nuevas dinámicas de acción colectiva en la frontera norte de México; y la profundización en el conocimiento de la construcción de ciudadanía vinculada con las migraciones nacionales y extranjeras. En términos teóricos, un siguiente análisis podría ahondar en la teoría de la gubernamentalidad para ampliar el estudio referente a los condicionamientos biopolíticos que están incidiendo en las movilidades humanas en todas sus dimensiones.

\section{Referencias}

Alarcón, R. \& Ortiz, C. (2017). Los haitianos solicitantes de asilo a Estados Unidos en su paso por Tijuana. Frontera Norte, 29(58), 171-179. 
Albicker, S., Félix, C., París, D., Pérez, G. \& Velasco, L. (2017). Emergencia migratoria y solidaridad de la sociedad civil en Tijuana, 2016-2017. México: El Colef-Conapred.

Altamirano, J. (25 de junio de 2017). Sin título [estado de Facebook]. Recuperado de https://www.facebook.com/groups/702704259881756/ permalink/8581461 84337562/

Benford, R. \& Snow, D. (2000). Framing processes and social movements: an overview and assessment. Annual Review of Sociology, 26, 611-639. https://doi.org/10.1146/annurev.soc.26.1.611

Benhabib, S. (2004). Los derechos de los otros. Extranjeros, residentes y ciudadanos. Barcelona: Gedisa.

Benhabib, S. (2006). Las reivindicaciones de la cultura. Igualdady diversidad en la era global. Buenos Aires: Katz Editores. https:/ / doi.org/10.2307/40184838

Boisier, S. (2002). Actores, asociatividad y desarrollo territorial en la sociedad del conocimiento (Acerca de la propuesta de 'clusterización' del Estado de Minas Gerais, Brasil). En Federacao das Industrias do Estado de Minas Gerais, Cresce Minas. Um Projeto Brasileiro (pp. 1-10). Mina Gerais: Federacao das Industrias do Estado de Minas Gerais.

Caren, N. (2007). Political process theory. En G. Ritzer (Ed.), Blackwell encyclopedia of sociology. https://doi.org/10.1002/9781405165518.wbeosp041

Chihu, A. (1999). Nuevos movimientos sociales e identidades colectivas. Iztapalapa, (47), 59-70.

Chihu, A. (2000). Melucci: la teoría de la acción colectiva. Argumentos, (37), 79-92.

Chihu, A. (2012). La teoría del framing: un paradigma interdisciplinario. Acta Sociológica, (59), 77-101. https://doi.org/10.22201/ fcpys.24484938e.2012.59.33119

Chihu, A. (2016). Marcos de acción colectiva en el movimiento de El Barzón. Región y Sociedad, 28(66), 321-337.

Coalición Pro Defensa del Migrante. (2016). Comunicado emitido el 8 de diciembre de 2016.

Collins, R. (2001). Social movements and the focus of emotional attention. En J. Goodwin, J. Jasper \& F. Polletta (Eds.), Passionate politics: emotions and social movements (pp. 27-44). Chicago: University of Chicago Press. https://doi.org/10.7208/chicago/9780226304007.003.0002

Comisión Nacional de Derechos Humanos. (2016). Derechos de las personas migrantes: una guía para las y los servidores públicos. México: CNDH. 
Comité Estratégico de Ayuda Humanitaria. (2018). [Página de Facebook]. Recuperado de https://www.facebook.com/search/ top $/$ ?q $=$ comit $\% \mathrm{C} 3 \%$ A $9 \% 20$ estrat $\% \mathrm{C} 3 \%$ A9gico $\% 20 \mathrm{de} \% 20$ ayuda $\% 20$ humanitaria $\% 20$ tijuana $\% 20$ (donaciones $\% 20 \mathrm{y} \% 20$ ayuda)

Consejo Ciudadano del Instituto Nacional de Migración. (2017). Grupos de trabajo: repatriaciones/visas por razones humanitarias. Caso: haitianos y africanos en la frontera norte de México. Recuperado de https:// www.gob.mx/cms/uploads/attachment/file/281220/Informe_Caso_Haitianos_y_Africanos.pdf

De la Garza, R. (2011). Las teorías de los movimientos sociales y el enfoque multidimensional. Estudios Politicos, (22), 107-138.

Delgado, R. (2007). Los marcos de acción colectiva y sus implicaciones culturales en la construcción de ciudadanía. Universitas Humanística, (64), 41-66.

Departamento de Seguridad Nacional. (2018a). Annual flow report. Refugees and asylees: 2016. Recuperado de https://www.dhs.gov/immigrationstatistics/refugees-asylees

Departamento de Seguridad Nacional. (22 de septiembre de 2016). Statement by Secretary Johnson concerning his directive to resume regular removals to Haiti. Comunicado de prensa. Recuperado de https://www.dhs.gov/ news/2016/09/22/statement-secretary-johnson-concerning-hisdirective-resume-regular-removals-haiti

Departamento de Seguridad Nacional. (25 de febrero de 2018b). Immigration statistics. Individuals granted asylum affirmatively or defensively. Recuperado de https://www.dhsgov/immigration-statistics/refuge es-asylees\#

Desidério, E. (2015). Espacio de fronteras entre instituciones participativas y migrantes en tránsito por Chiapas. Andamios, 12(28), 91-116.

Desidério, E. (2016). Gubernamentalidad representativa en la migración: aportes de transnacionalismo en la política de gestión migratoria en Chiapas. Revista Internacionales, 2(4), 136-174.

Estupiñán, M. (2014). La gestión internacional de las migraciones como una racionalidad política. Migraciones Internacionales, 7(3), 249-259.

Foucault, M. (2006). Seguridad, territorio, población: curso en el Collège de France 1977-1978. Buenos Aires: Fondo de Cultura Económica.

Foucault, M. (2007). Nacimiento de la biopolitica: curso en el Collège de France 1978-1979. Buenos Aires: Fondo de Cultura Económica. 
Garretón, M. (1985). Actores sociopolíticos y democratización. Revista Mexicana de Sociología, 47(4), 5-16. https://doi.org/10.2307/3540572 Garretón, M. (2002). La transformación de la acción colectiva en la América Latina. Revista Cepal, (76), 7-24.

Ghosh, B. (2012). A snapshot of reflection on migration management. Is migration management a dirty word? En M. Gieger \& A. Pécoud (Eds.), The new politics of international mobility. Osnabrück: Univeristat Osnabrück. Citado en Estupiñán, M. (2017). Migración y derechos humanos: de la gobernanza al diálogo social. Dfensor, (6), 5-9.

Goffman, E. (1974). Frame analysis: an essay on the organization of experience. Cambridge: Harvard University Press. https://doi.org/10.1176/ ajp.132.10.1093-a

Goffman, E. (2006). Frame analysis. Los marcos de la experiencia. Madrid: Centro de Investigaciones Sociológicas.

Goodwin, J., Jasper, J. \& Polletta, F. (Eds.). (2001). Passionate politics: emotions and social movements. Chicago: University of Chicago Press. https:// doi.org/10.7208/chicago/9780226304007.001.0001

Homeland Security. (2016). Southwest border unaccompanied alien children statistics FY 2016, Estados Unidos, U.S. Customs and Border Protection. Recuperado de http://www.cbp.gov/newsroom/stats/southwest-border-unaccompanied-children/fy-2016\#

Instituto Nacional de Migración. (2016). Oficio de salida de la estación migratoria siglo XXI con fines de regularización. Documento personal.

Instituto Nacional de Migración. (2017). Boletín mensual de estadísticas migratorias, 2016. Ciudad de México: Instituto Nacional de Migración.

Instituto Nacional de Migración. (2018). Boletín mensual de estadísticas migratorias, 2017. Ciudad de México: Instituto Nacional de Migración.

Jiménez, C., Moreno, J., Figueroa, S. \& Barajas, M. (2012). Una aproximación al perfil de las organizaciones civiles que atienden a migrantes en los Estados de Baja California y Sonora. En J. Moreno, A. Sández \& M. López (Coords.), Éxodos, veredas y muros: perspectivas sobre la migración (pp. 109-139). Mexicali: UABC.

McCarthy, J. \& Zald, M. (1973). The trend of social movements in America: professionalization and resource mobilization. Morristown: General Learning Press. Melucci, A. (1999). Acción colectiva, vida cotidiana y democracia. México: El Colegio de México. 
Melucci, A. \& Massolo A. (1991). La acción colectiva como construcción social. Estudios Sociológicos, 9(26), 357-364.

Nava, A. (1997). De la acción colectiva al movimiento social. El caso de la Cooperativa Pascual. Revista Mexicana de Sociología, 59(3), 301-316. https://doi.org/10.2307/3541382

Olson, M. (1965). The logic of collective action. Cambridge: Harvard University Press. https://doi.org/10.1007/978-1-349-20313-0_5

Ostrom, E., Ahn, T. \& Olivares, C. (2003). Una perspectiva del capital social desde las ciencias sociales: capital social y acción colectiva. Revista Mexicana de Sociología, 65(1), 155-233. https://doi.org/10.2307/3541518

París, D. \& Müller, P. (2016). La incidencia política de las organizaciones pro migrantes en México. En L. Escala (Coord.), Asociaciones inmigrantesy fronteras internacionales (pp. 255-281). México: El Colegio de la Frontera Norte-El Colegio de San Luis.

Piven, F. \& Cloward, R. (1977). Poor people's movements: why they succeed, how they fail. Nueva York: Vintage Books. https:/ / doi.org/10.1093/sw/25.1.76-a

Puricelli, S. (2005). La teoría de movilización de recursos desnuda en América Latina. Revista Theomai, (12), 1-12.

Red de Documentación de las Organizaciones Defensoras de Migrantes (Redodem). (2017). El Estado indolente: recuento de la violencia en las rutas migratorias y perfiles de movilidad en México. México: Redodem.

Secretaría de Desarrollo Social (Sedesol). (11 de noviembre de 2016). Convocatoria dirigida a organizaciones de la sociedad civil (OSC) con domicilio fiscal en los municipios que se indican, para presentar proyectos de inclusión social enfocados a la atención del flujo extraordinario de migrantes (FM) en Tijuana y Mexicali, Baja California, así como en Tapachula, Chiapas; dentro del Programa de Coinversión Social. Diario Oficial de la Federación, 45-52. Recuperado de http:/ /dof.gob.mx/ nota_detalle.php?codigo $=5460711 \&$ fecha $=11 / 11 / 2016$

Siegel, D. (2009). Social networks and collective action. American Journal of Political Science, 53(1), 122-138. https://doi.org/10.1111/j.15405907.2008.00361.x

Silva, A. (2015). Estrategias de tránsito de adolescentes centroamericanos independientes: enfrentando la frontera vertical en México. REMHU, Revista Interdisciplinar da Mobilidade Humana, 23(44), 99-117. https:/ / doi.org/10.1590/1980-85852503880004407 
Tarrés, M. (1992). Perspectivas analíticas en la sociología de la acción colectiva. Estudios Sociológicos, 10(30), 735-757.

Tilly, C. (1978). From mobilization to revolution. Reading: Addison-Wesley.

Varela, A. (2015). La 'securitización' de la gubernamentalidad migratoria mediante la 'externalización' de las fronteras estadounidenses a Mesoamérica. Con-temporánea, 2(4), 1-19.

Varela, A. (2016). Luchas migrantes en contextos de tránsito migratorio, el caso del Movimiento Migrante Centroamericano. REMHU, Revista Interdisciplinar da Mobilidade Humana, 24(48), 31-44. https://doi. org/10.1590/1980-85852503880004803

Yee, J. (2017). Caracterizando a los solicitantes de asilo a Estados Unidos: el caso de los haitianos en 2016. En P. Murphy, R. Alarcón, M. L. Coubes, J. Yee \& M. Cárdenas, Vidas en vilo. Historias y testimonios de migrantes internacionales (pp. 53-81). Tijuana: Ediciones ILCSA. 